\title{
Experimental Study of Thermoelectric Conversion Efficiency and Cold Side Thermal Management
}

\author{
Vamsi Vegamoor ${ }^{1,2}$, Muhammad Sajid ${ }^{2,3^{*}}$, Yasser M. Al Hamidi², and Ibrahim Hassan ${ }^{2}$ \\ ${ }^{1}$ Texas A\&M University, College Station, TX, U.S.A. \\ ${ }^{2}$ Texas A\&M University at Qatar, Doha, Qatar. \\ ${ }^{3}$ School of Mechanical \& Manufacturing Engineering (SMME), National University of Sciences \& Technology (NUST), Islamabad, \\ Pakistan.
}

\begin{abstract}
Thermoelectric generator (TEG) while offering the advantage of operational reliability are constrained by limited efficiencies. This paper, which is from an undergraduate research project, focusses on the contribution of cold side thermal management of commercially available thermoelectric generators towards the thermal to electrical conversion efficiency for a range of hot side temperatures. Electric heating elements are used to vary the heat flux to the TEG while conventional active and passive methods employing air and water as a medium are used for dissipating heat from the cold side of TEGs. Both thermal and electrical performance parameters of the TEGs are recorded for various ambient conditions in an indoor facility corresponding to naturally occurring wind conditions. At the end, the utility and effectiveness of the cooling methods are quantified for the range of operating temperatures.
\end{abstract}

\section{Introduction}

With the current state of energy and its availability, there have been several attempts at developing environmentally conscious means to generate electricity from simple sources such as temperature differences. Thermoelectric generators (TEG) use an array of semiconductors to generate voltage when presented with a temperature difference. Essentially relying on the material dependent Seebeck effect [1] as seen below in (1) and physically can be quantified as the generation of an electromotive field in a temperature difference.

$$
E_{\text {emf }}=-\alpha \Delta T
$$

However, from the current literature available on TEGs, the efficiency of these devices falls below 5-8\% [2] leading to a major concern in their inability to provide designed performance. Therefore, TEGs are seen as devices that would make use of residual heat from its surroundings to generate small voltages while providing a reasonable cost to benefit ratio. TEGs can be used to convert the waste heat given off by electrical instruments, vehicles and numerous other systems, to generate power $[3,4]$ as well as for heat dissipation and sensing thermal energy [5]. Research on the various uses suggests that TEGs could be used as coolers, high and low power generation, and superconductors.

Another use that is being investigated is the possibility of using TEGs in Wireless Sensor Network (WSN) applications due to the longer lifespan and smaller physical dimensions compared to primary batteries, cost efficiency and the use of ambient waste heat sources

\footnotetext{
* Corresponding author: $\underline{\text { m.sajid@,smme.nust.edu.pk }}$
}

which results in a generally better environment [6]. Commercially, TEGs are being considered for their energy generation capacities leading to implementation in exhaust fumes [7] and for the development of electrically independent combustion gas stoves that can use TEGs to power auxiliary electrical components without being connected to a power grid, giving the possibility for use in remote locations [8]. TEGs have also impacted space exploration where they are powered by radioactive emissions to support onboard electronics during long trajectories coupled with restrictions in fuel carrying capacity $[9,10]$.

Several works have investigated the mechanisms by which various factors affect the output, and as a result the efficiency of the TEGs. These studies have focused on a diverse range of varying parameters, resulting in different setups and analysis methodology. This necessitated a study of cold side thermal management of thermoelectric generators keeping, varying only the heat dissipation strategy while all other parameters remain same. Thereby allowing a better assessment of cooling methodologies and guidelines for thermal management.

A significant assumption of the current experiment is based on the work by Apertet et al [11] which highlights the importance of assuming thermal environment conditions and the resulting effect on the maximum output power by distinguishing two models. It was concluded that in order to simultaneously maximize efficiency and power output, the Norton model provided the more feasible solution, which has been utilized in the current experiment. In order to analyze the external and 
internal factors affecting performance Sabino et. al [12] using aluminum fins, concluded that the temperature gradient and voltage increased in similar fashions. Additionally, W.-H. Chen et al.[13] study on geometric effect on cooling power and performance and the study by Meng et al [14] concluded that the heat sink temperature affected the cooling power more than the heat load. Also recognizing the effect of heat loss through geometry as mentioned in Niu et al[15], W.-H. Chen et al. experimented on the various geometric conditions affecting the TEG to generate numerical models of the hot and cold side while assuming steadystate conditions, constant thermal contact resistance and temperature dependent TEG material properties. A similar experiment by Gomez et. al [16] comes to the same conclusion after analyzing the influence of current variance and thermal resistances on various geometric and working conditions.

It still remains challenging to achieve design efficiency levels and identify operating conditions and parameters for their optimum usage. While previous works test the various physical, thermal and electrical factors affecting the TEG's performance, many concentrate on the cooling design itself and some groups tend to focus on different cases of a single concept. Therefore this project aims to provide a comprehensive comparison of various cooling methods on a single TEG to examine if design specifications of efficiency are realistic.

\section{Experimental Methods}

\subsection{Apparatus}

The experimental setup consists of a 40 x $40 \mathrm{~mm}$ thermoelectric module obtained from Tecteg, Canada, with a stated peak efficiency of $\sim 6 \%$ at a cold side temperature of $30^{\circ} \mathrm{C}$ and a $\Delta \mathrm{T}$ of $100-150^{\circ} \mathrm{C}$. The thermal receiver end of the module was attached to a hot plate for a range of heat fluxes, while various heat sinks were attached to the cold side of the module for heat dissipation. A complete list of all equipment used to perform the experiments is listed below.

Table 1. List of equipment

\begin{tabular}{|l|l|}
\hline \multicolumn{1}{|c|}{ Equipment } & \multicolumn{1}{c|}{ Description } \\
\hline Heater & $\begin{array}{l}\text { Ceramic Hotplate \& Omega } \\
\text { Silicon Heater }(45 \mathrm{~W} \\
\text { Maximum heat power } \\
\text { output) }\end{array}$ \\
\hline Thermocouples & $\begin{array}{l}\text { Omega, Type T, 0.25mm \& } \\
\text { Omega Type K, } 0.125 \mathrm{~mm}\end{array}$ \\
\hline Thermal Paste & Silicon Paste \\
\hline Right & 20 \\
\hline
\end{tabular}

The thermal grease and the hot plate heater were supplemented with thermal pad and Omega silicon heater due to their effective performance. Similarly, fine

\footnotetext{
Corresponding author: $\underline{\text { m.sajid@smme.nust.edu.pk }}$
}

wired thermocouples of $0.125 \mathrm{~mm}$ diameter were used to reduce heat loss between the contact surfaces. The following heat sinks were used for heat dissipation.

Table 2. List of cooling devices used in study

\begin{tabular}{|l|l|}
\hline \multicolumn{1}{|c|}{ Equipment } & \multicolumn{1}{c|}{ Description } \\
\hline Fin & $\begin{array}{l}\text { Aluminum fins } \\
\text { (manufactured to the outer } \\
\text { dimensions of TEG) }\end{array}$ \\
\hline $\begin{array}{l}\text { Hybrid Passive } \\
\text { Cooling }\end{array}$ & $\begin{array}{l}\text { Fanless CPU Cooler from } \\
\text { NoFanTM Corporation } \\
\text { (model: CR-95C) }\end{array}$ \\
\hline Water Tank & $\begin{array}{l}\text { Aluminum tank } \\
\text { (manufactured to the outer } \\
\text { dimensions of TEG) }\end{array}$ \\
\hline Wind Tunnel & $\begin{array}{l}\text { Texas A\&M University at } \\
\text { Qatar Facilities }\end{array}$ \\
\hline
\end{tabular}

\subsection{Experimental setup}

The TEG was tested under the following conditions:

- No added cooling (natural convection)

- Passive Air Cooling: Fin

- Passive Water Cooling: Water Tank

- Hybrid Cooling: NoFan ${ }^{\mathrm{TM}}$ CPU Cooler

- Active Air Cooling: Wind Tunnel

- Active Water Cooling: Heat Exchanger

Each of the above experiments will be discussed separately, however for all, there is a general set up which was consistently used as shown in Fig. 1.a below. The difference in the setups was in the type of cooling attachment placed above the TEG.

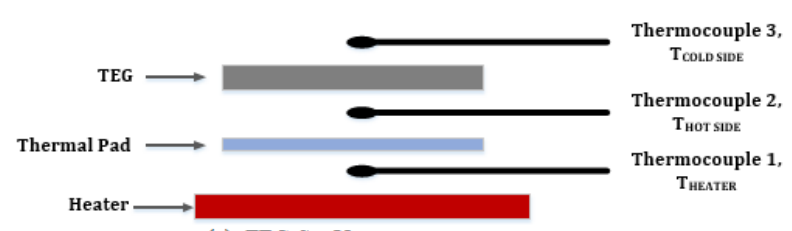

(a) TEG Set Up

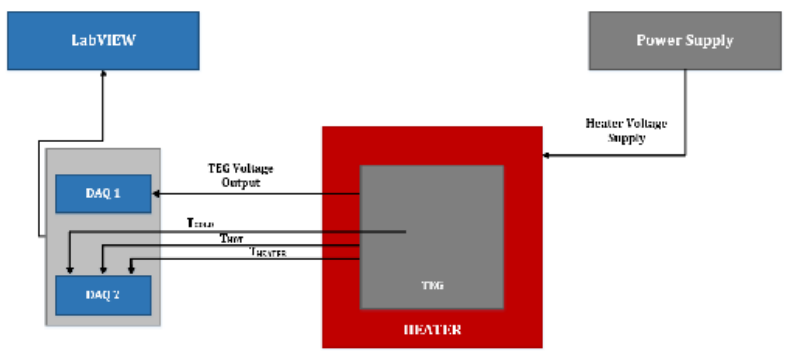

(b) General Experimental Configuration

Fig. 1: Schematic representation of experimental facility

\subsubsection{Test procedure}

An overview of the five experimental setups under passive and active cooling that were pursued in the current work is depicted in Fig. 1.b. The methodology followed for each experimental run is described in the following sections.

No Added Cooling: In this case natural convection was the sole mechanism for heat removal from the thermoelectric module. Thermal grease was used to ensure good thermal contact between the heater surface 
and the hot side of the thermoelectric device. The heater was set to temperatures between $30^{\circ} \mathrm{C}$ and $70^{\circ} \mathrm{C}$ because and temperature and voltage data was collected at a sampling rate of $3 \mathrm{~Hz}$. The internal resistance was calculated manually by using an external resistor, of known resistance, placed in series with the TEM and an ammeter to measure the current. The power output was calculated using this resistance in order to quantify the efficiency of the device.

Passive Air Cooling: A fin was used to provide heat dissipation from the TEG placed on the heater, with fine thermocouples for acquisition of thermal data. The voltage supplied to the heater was controlled, which allowed for measurement of power input. This was later used to measure the efficiency of the TEG under the specified cooling method. All temperature and voltage measurements were collected using LabVIEW at a continuous sampling rate of $1 \mathrm{~Hz}$. The hot side of the TEG was maintained at a constant temperature after achieving steady state while the cold side varied. The test was repeated for various hot side temperatures - and corresponding voltage inputs of $30 \mathrm{~V}, 40 \mathrm{~V}$ and $50 \mathrm{~V}-$ whilst collecting temperature data on the hot and cold side as well as the voltage output. The heater thermocouple was used to ensure that data collection did not begin prior to steady state. The internal resistance of the TEG at $4.5 \Omega$, as already specified by the manufacturer, was used to calculate the power output.

Passive Water Cooling: The process described above was repeated with a water tank as the cooling method. The tank was fabricated from $1 \mathrm{~mm}$ aluminum sheets. Water was kept at room temperature and the heat temperature was varied. For this method, a broader range of input voltages for the heater for used, from $30 \mathrm{~V}$ to $70 \mathrm{~V}$ in increments of $10 \mathrm{~V}$, in order to reach higher hot side temperatures comparable to the heat dissipation potential associated with water based cooling methods. While the lower bound was kept in same range is previous experiments for continuity.

Hybrid Cooling: In this case a commercial CPU cooler manufactured by NoFan ${ }^{\mathrm{TM}}$ was employed for heat dissipation from the cold side of the TEG. The NoFan ${ }^{\mathrm{TM}}$ cooler is considered as a hybrid device since there is a liquid coolant in the cylindrical fins which goes through a phase change as it absorbs heat from the cold side of the TEG, while heat rejection takes place from the fins aided by natural convection. The fan less cooler uses patented 'IcePipe' technology and yields a maximum TDP (thermal design power) of 95 watts. Its functioning is based on natural circulation of the liquid coolant through capillary action. Since no additional cooling is needed, it is a passive cooler with a phase change process. This cooler was chosen due to the relatively newer technology using phase change cooling which results in a noiseless, dust free and low maintenance way to cool PC systems and offers a hitherto unexplored TEGs cooling techniques. The complete experimental setup is shown in Fig. 2. The Data Acquisition system is

\footnotetext{
* Corresponding author: $\underline{\text { m.sajid@smme.nust.edu.pk }}$
}

towards the left and was maintained same for all cooling methods.

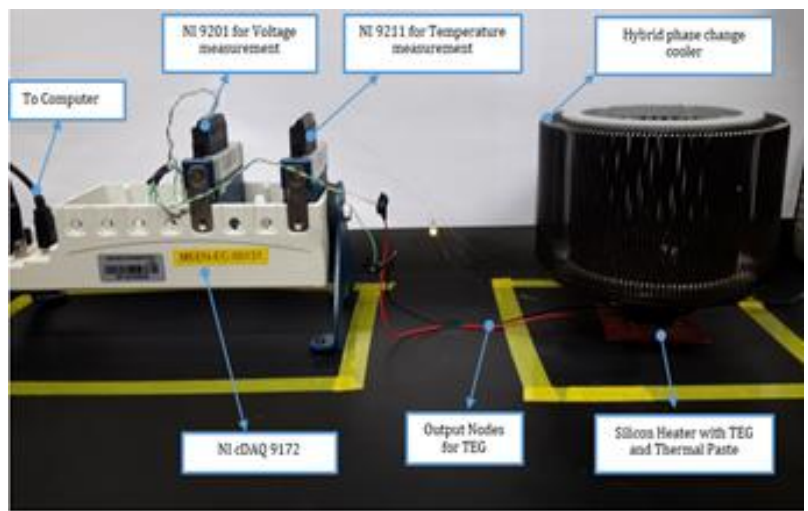

Fig. 2: Experimental Setup for Hybrid Cooling Method

Active Air Cooling: The TEG was placed in a wind tunnel and fitted with the fin used in the passive air cooling experiment. The heater was insulated using cardboard to prevent heat loss, as shown in Figure 3. The experiment was performed for two wind speeds and 5 input voltages mentioned earlier.

Active Water Cooling: The final cooling method was performed using a heat sink which uses circulating water as the active cooling agent. The flowrate of the water was kept constant and five measurements were collected.

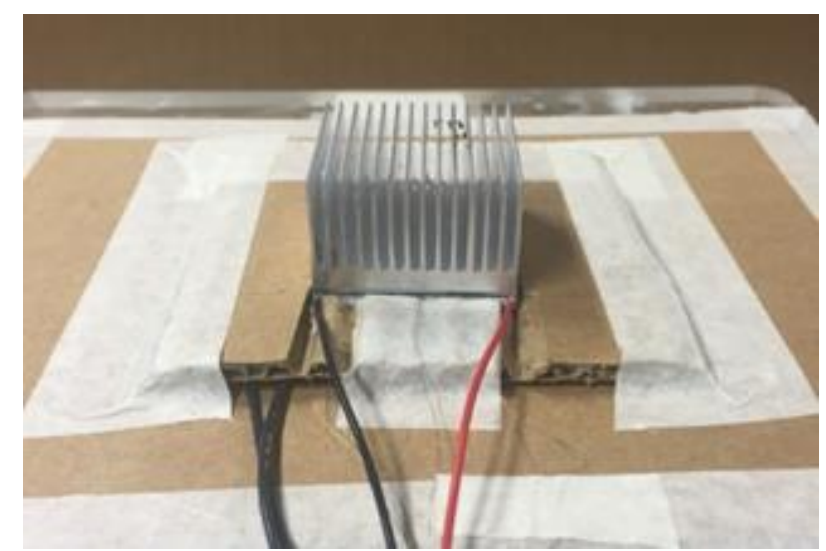

Fig. 3: Wind Tunnel Experimental Set Up

\section{Results}

Data from the three thermocouples and the open circuit voltage was measured. The heat flux input was changed by varying the input $\mathrm{DC}$ voltages to the heater. For the case of passive air cooling and no-cooling, the range of voltages supplied were 30VDC, 40VDC and 50VDC.

Since the Silicon heater that was used was rated for a maximum voltage input of $115 \mathrm{VDC}$, the manufacturer provided the following equation to calculate the heat power given out by the heater at any voltage below the maximum:

$$
P_{\text {Actual }}=P_{\text {Rated }} *\left(\frac{V_{\text {Actual }}}{V_{\text {Max }}}\right)^{2}
$$


Consequently, Table 3 shows the net heat flux provided by the heater at the various voltage settings that were used throughout this experiment.

Table 3: Relation of Heater Supply Voltage and Heat Flux

\begin{tabular}{|r|c|c|c|c|c|}
\hline $\begin{array}{r}\text { Supply } \\
\text { Voltage(V) }\end{array}$ & $\mathbf{3 0}$ & $\mathbf{4 0}$ & $\mathbf{5 0}$ & $\mathbf{6 0}$ & $\mathbf{7 0}$ \\
\hline $\begin{array}{r}\text { Input } \\
\text { Heat } \\
\text { Power(W) }\end{array}$ & 3.1 & 5.4 & 8.5 & 12.2 & 16.7 \\
\hline $\begin{array}{r}\text { Heat Flux } \\
\left(\mathbf{W} / \mathbf{m}^{2}\right)\end{array}$ & 478.5 & 850.7 & 1329.2 & 1914.0 & 2605.2 \\
\hline
\end{tabular}

Instead of maintaining a constant hot side temperature, the input heat flux was kept constant, which is a more practical scenario since most waste heat sources have a stable heat energy loss rather than a persistent temperature. Figure 4 shows the voltage readings collected over a range of cold side temperatures. As expected, an increase in the cold side temperature (resulting in a decrease in the temperature gradient over the TEG) resulted in the decrease in the output voltage. The uncertainty associated with the quantities on the vertical and horizontal axis are also displayed in each of the following graphs.

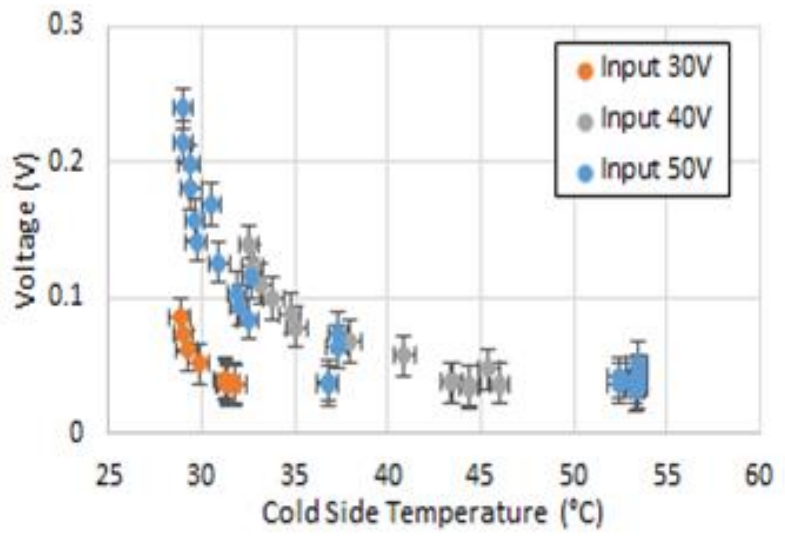

Fig. 4: Voltage Output vs. Cold Side Temp. for No Cooling

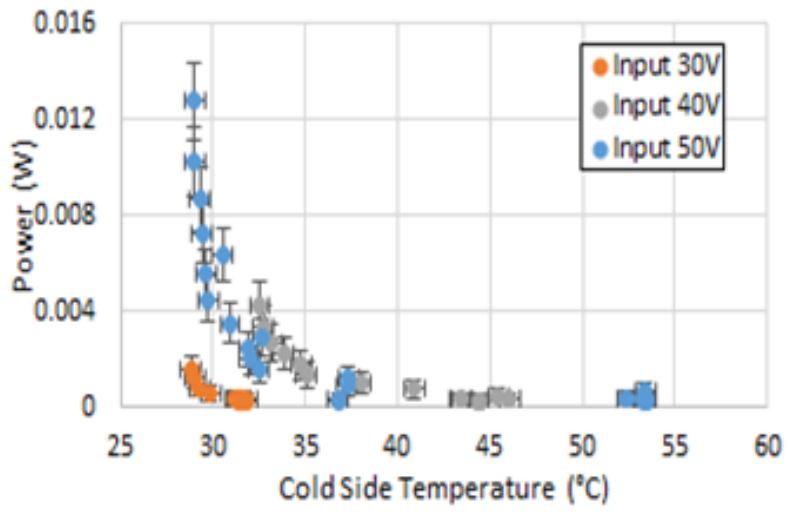

Fig. 5: Power Output vs. Cold Side Temp. for No Cooling

From the open circuit voltage, and the known internal resistance of the thermoelectric generator, the net maximum power output from the generator was calculated, as shown in Fig. 5. The internal resistance of TEGs are known to vary with temperature. Resistance curve were obtained from the manufacturer for different hot side and cold side temperatures.

Following this, the heat power delivered by the Silicon heater from Table 3 was considered as the input power and the efficiency of the TEG as a system was calculated. The resulting graph of the trend of efficiency against cold side temperature at various heater input voltages is shown below in Fig. 6 .

This process was repeated for other cooling methods. The efficiency of the system when a fin was used to cool the TEG with free convection is shown in Figure 7. It can be noted that the values for the efficiency here are significantly higher than those in Figure 6, when no cooling method was implemented.

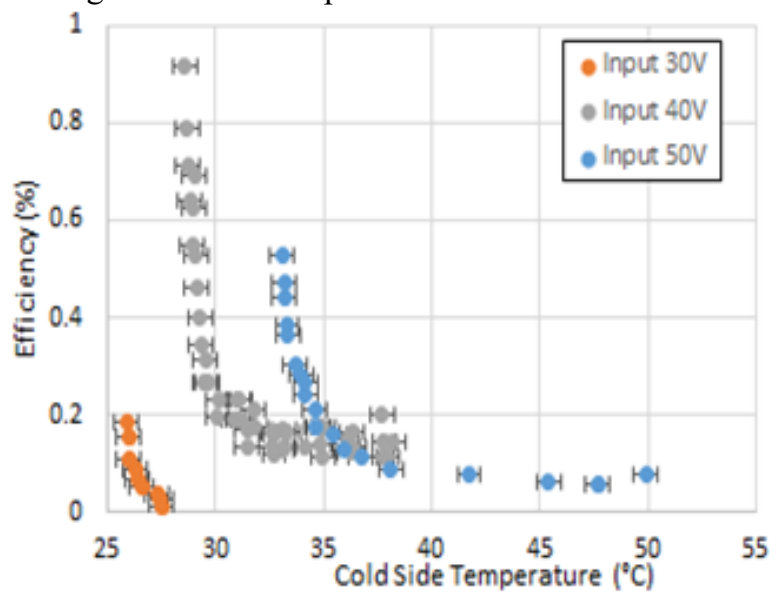

Fig. 6: Efficiency vs. Cold Side Temp. for Fin Cooling

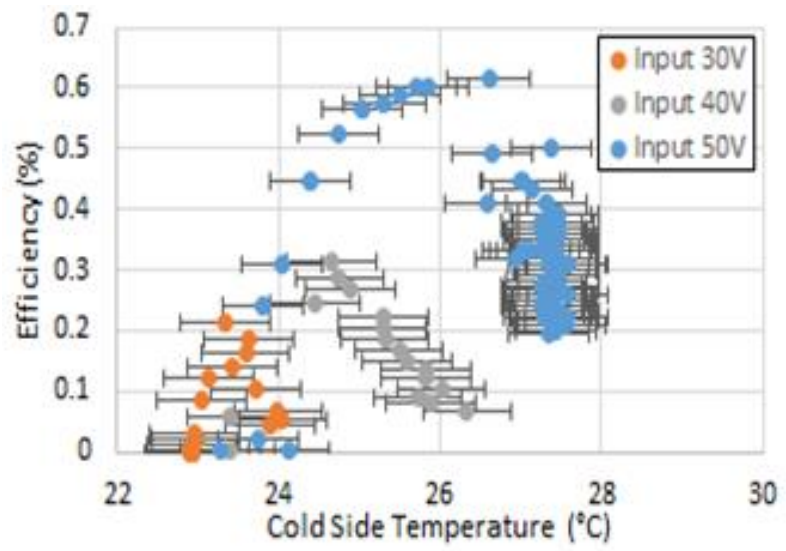

Fig. 7: Output Efficiency vs. Cold Side Temperature for Hybrid Cooling

Next, the Hybrid NoFan ${ }^{\mathrm{TM}} \mathrm{CPU}$ cooler was used to draw heat away from the cold side of the TEG. The data collected was somewhat unexpected and did not display a clear trend. One possible reason is that the heater was not able to supply sufficient heat energy to the TEG, compared to the energy being dissipated by the cooling system. The efficiency of the system at various input levels are displayed in Figure 7.

This complete process was repeated for four other cooling methods: Passive water cooling, Active Water

\footnotetext{
* Corresponding author: $\underline{\text { m.sajid@smme.nust.edu.pk }}$
} 
cooling, and forced convection using a wind tunnel at two different air velocities (Low Speed: $2.9 \mathrm{~m} / \mathrm{s}$ and High Speed: $6.4 \mathrm{~m} / \mathrm{s}$ ). This resulted in a total of 16 runs. During these runs variations in efficiencies were observed after passage of settling time. The observed peak efficiencies that were obtained for each cooling method are listed in Table 4. Highest efficiencies were obtained by active air cooling. The peak efficiencies during each of those runs is presented in the bar graph in Figure 8. The red vertical bars show the uncertainty associated with each measurement.

Table 4: Peak efficiencies for different cooling methods

\begin{tabular}{|c|c|c|c|c|}
\hline $\begin{array}{c}\text { Heater } \\
\text { Input } \\
\text { Level } \\
\text { (Volts) }\end{array}$ & $\begin{array}{c}\text { Passive } \\
\text { Water }\end{array}$ & $\begin{array}{c}\text { Active } \\
\text { Water }\end{array}$ & $\begin{array}{c}\text { Active } \\
\text { Air Low } \\
\text { Speed }\end{array}$ & $\begin{array}{c}\text { Active Air } \\
\text { High } \\
\text { Speed }\end{array}$ \\
\hline 40 & 0.05 & 0.34 & 2.73 & 1.98 \\
\hline 50 & 0.13 & 0.49 & 3.17 & 4.22 \\
\hline 60 & 0.40 & 0.59 & 4.68 & 2.66 \\
\hline 70 & 0.77 & 0.82 & 4.51 & 4.41 \\
\hline
\end{tabular}

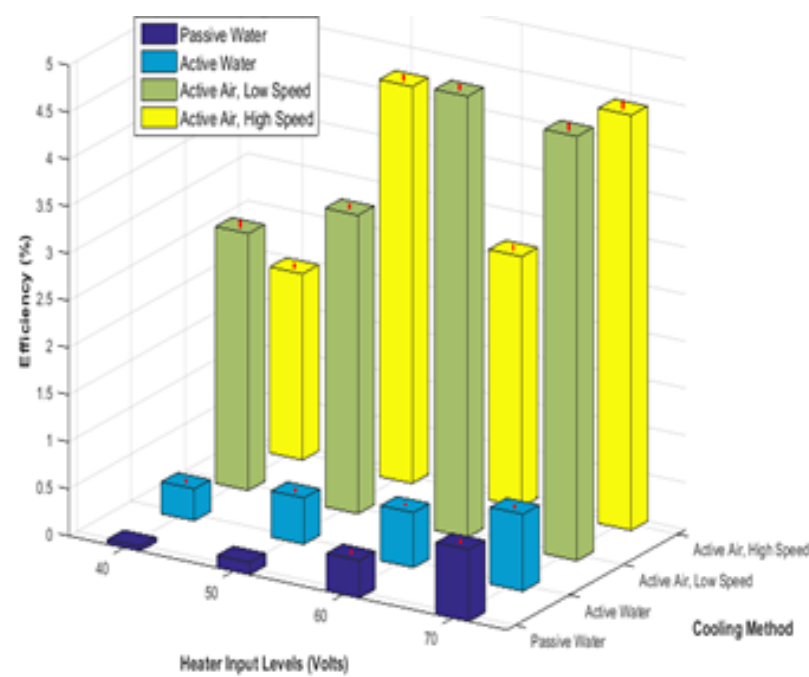

Fig. 8: Peak Output Efficiency vs. Input Heat Flux

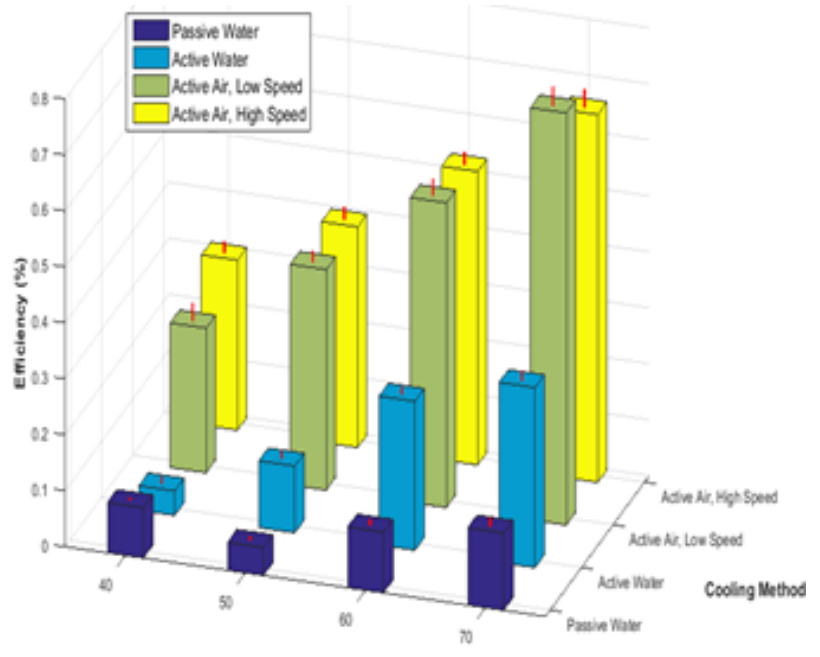

Fig. 9: Steady state efficiency vs. input heat flux
While the peak efficiency only lasts for a short duration in each run, a more important value is the steady state efficiency of the system. Any large scale implementation of waste heat recovery will need to be run continuously and hence studying the steady state efficiency is of paramount importance. Figure 9 displays the steady state values for each of the sixteen trials.

Table 5: Steady state efficiencies for different cooling methods

\begin{tabular}{|c|c|c|c|c|}
\hline $\begin{array}{c}\text { Heater } \\
\text { Input } \\
\text { Level } \\
\text { (Volts) }\end{array}$ & $\begin{array}{c}\text { Passive } \\
\text { Water }\end{array}$ & $\begin{array}{c}\text { Active } \\
\text { Water }\end{array}$ & $\begin{array}{c}\text { Active } \\
\text { Air Low } \\
\text { Speed }\end{array}$ & $\begin{array}{c}\text { Active } \\
\text { Air High } \\
\text { Speed }\end{array}$ \\
\hline 40 & 0.09 & 0.04 & 0.26 & 0.30 \\
\hline 50 & 0.05 & 0.12 & 0.39 & 0.39 \\
\hline 60 & 0.11 & 0.27 & 0.54 & 0.52 \\
\hline 70 & 0.14 & 0.32 & 0.74 & 0.66 \\
\hline
\end{tabular}

A key objective of this work was to study different cold side management techniques from the perspective of overall efficiency. In order to compare the different sample and statistically analyze the data, an Analysis of Variance (ANOVA) test was carried out. A two-way ANOVA without replication was used to determine whether the cooling method and the input heat flux have an effect on the peak efficiency. The results of the analysis are presented in Table 6, where the heat flux is represented by the rows and the cooling methods by columns. At a $75 \%$ confidence interval, both factors have a significant effect on the data, with the cooling method having a greater effect on the peak efficiency.

Table 6: ANOVA for all cases with $75 \%$ confidence

\begin{tabular}{|l|c|c|c|c|c|c|}
\hline $\begin{array}{c}\text { Source } \\
\text { of } \\
\text { Variation }\end{array}$ & SS & df & MS & F & $\begin{array}{c}\text { P- } \\
\text { value }\end{array}$ & $\begin{array}{c}\text { F } \\
\text { crit }\end{array}$ \\
\hline Rows & 0.60 & 1 & 0.60 & 1.68 & 0.24 & 1.62 \\
\hline Columns & 20.81 & 6 & 3.47 & 9.70 & 0.01 & \\
\hline Error & 2.14 & 6 & 0.36 & & & \\
\hline & & & & & & 1.78 \\
\hline Total & 23.56 & 13 & & & & \\
\hline
\end{tabular}

Another ANOVA was applied to determine whether the wind speed of the active air cooling method has an effect on the peak efficiency, shown in Table 7 . Even with a confidence interval as low as $75 \%$, the wind speed does not have a significant effect on the peak efficiency.

Table 7: ANOVA for wind speeds in active air cooling.

\begin{tabular}{|l|c|c|c|c|c|c|}
\hline $\begin{array}{c}\text { Source } \\
\text { of } \\
\text { Variation }\end{array}$ & SS & df & MS & F & $\begin{array}{c}\text { P- } \\
\text { value }\end{array}$ & $\begin{array}{c}\text { F } \\
\text { crit }\end{array}$ \\
\hline Rows & 10.45 & 4 & 2.61 & 3.89 & 0.11 & 2.06 \\
\hline Columns & 0.24 & 1 & 0.24 & 0.35 & 0.58 & 1.81 \\
\hline Error & 2.69 & 4 & 0.67 & & & \\
\hline & & & & & & \\
\hline Total & 13.37 & 9 & & & & \\
\hline
\end{tabular}

\section{Discussion}

\footnotetext{
*Corresponding author: $\underline{\text { m.sajid@smme.nust.edu.pk }}$
} 
General Temperature and Voltage Characteristics. It was observed, graphically, that the voltage data was excessively noisy, and prohibited any analytical study. Hence, a Low-Pass Butterworth filter was applied via MATLAB with a normalized cutoff frequency of 0.01 . Additionally, $\Delta \mathrm{T}$ was initially plotted as a function of time.

It was noted that both voltage and $\Delta \mathrm{T}$ have similar behavior with time. Therefore there is a general correlation between output voltage produced and temperature difference applied across the TEG as confirmed by the conclusions drawn by Sabino et. al[12] The voltage output was then plotted against $\Delta \mathrm{T}$ at specific points to find the Seebeck coefficient of the device which was the slope of the linear fit and was valued at $0.022 \mathrm{~V} / \mathrm{K}$ which is comparable to that found in literature[17], $0.0119 \mathrm{~V} / \mathrm{K}$, for the corresponding model of the Peltier device.

Passive Air Cooling. From the data as seen in Fig. 4. obtained when the TEG was not provided with external cooling sources, i.e., was placed in an open natural environment, that the curve with the highest heat flux (at $50 \mathrm{~V}$ input) yielded the highest voltage due to a larger temperature gradient. It can also be noted that after a period of time, the cold side temperature heated up gradually, and therefore reduced the temperature gradient. This results in the voltage values no longer displaying drastic changes. Implying that at steady state, a more or less constant temperature difference would result in a nearly constant voltage output. Additionally, from the plots it is evident that the same $\nabla \mathrm{T}$ does not yield the same voltage output. Therefore, a conclusion that can be drawn is that the voltage does not depend solely on the temperature gradient but also the base hot side temperature as well. It also was noted that efficiency drastically drops after certain cold side temperatures and the largest drop was observed in the curve with the highest hot side temperature, i.e. the rate of decay of the efficiency curves increases as the hot side temperature increases.

At some points however, it was noted that the efficiency of the curve with $\mathrm{TH}$ of $56 \mathrm{oC}$ showed a higher efficiency than the TH of $73^{\circ} \mathrm{C}$ curve. Possible reasons for this include, but are not limited to, the initial cold side temperature being high for the case of $\mathrm{TH}$ of $73^{\circ} \mathrm{C}$ implying that the cold side had some previous stored thermal energy possibly from the previous runs. Additional possible sources of error include lack of insulation causing unquantified heat loss, thermal paste properties like low thermal conductivity leading to a significant amount of heat loss, non-uniform heater properties which would result in uneven heating of the TEG resulting in altered values of voltage and inherent uncertainty and noise associated with the DAQs.

A general observation from Fig. 7. was that when the aluminum fin was placed on the TEG was that the efficiency significantly increased while the natural state of the TEG resulted in a maximum efficiency of about
$0.158 \%$ the case with the fin yielded an efficiency of over $0.9 \%$ therefore justifying Sabino et. al [12] and A. Date et al.'s [5] exploration into passive air cooling methods using fins. Additionally, Fig. 9. displays the efficiency curves for the hybrid cooling method and the abnormal shape suggests that perhaps the hot side was not constant throughout and could have been cooled by the cooler, resulting in a drop in temperature difference, causing the drop in efficiency. This could also the reason the method yielded a low peak efficiency of approximately, $0.6 \%$.

Active Air Cooling. For the data collected when the TEG and fin setup was placed in a wind tunnel, it was noted that the run at the lower velocity of $2.9 \mathrm{~m} / \mathrm{s}$ reaches the higher efficiency of nearly $4.75 \%$. Two anomalies are noted; firstly, it was assumed that the run with the higher wind speed of $6.4 \mathrm{~m} / \mathrm{s}$ (which had an efficiency of nearly $4.5 \%$ ) would have a higher efficiency based on the fact that a higher wind speeds results in more heat transfer and as a result a longer sustained temperature difference which would give a larger efficiency. After statistical analysis however, since the difference was not significantly large, we can make the assumption that wind speeds do not significantly affect the efficiency of a TEG. The second anomaly recognized was that the highest efficiency was reached during the run conducted at $60 \mathrm{~V}$ input to the heater (which is about $1900 \mathrm{~W} / \mathrm{m} 2$ ). One possible explanation for this could be that the time between the two runs at the highest input voltages 60 and $70 \mathrm{~V}$ ended with the cold side still retaining residual heat energy leaving the $70 \mathrm{~V}$ trial's cold side with a higher starting temperature thereby limiting the possible temperature difference. It should be assumed that with a longer gap, observing the trend in data, the larger input hot side temperature would result in a larger efficiency, which in this case would reach and possibly go beyond $5 \%$ making it one method and set of conditions that meet manufacturer specifications. An interesting point to note is that the average efficiency of the individual runs lie within a small range as seen in Fig. 10. since all the efficiencies in both runs fall to between $0-1 \%$ at steady state.

Passive Water Cooling. While the general trend of the data in Figures 9 and 10 conforms to our assumptions and previous behavior, it should be noted that the difference between the peak efficiencies for the $60 \mathrm{~V}$ input voltage run with $0.4 \%$ and $70 \mathrm{~V}$ run with nearly $0.8 \%$ is pretty significant while the steady state efficiencies between $0.1 \%$ and about $0.15 \%$ in the former respective order. This implies that while considering this method the input hot side temperature does not significantly affect the efficiency during steady state.

Active Water Cooling. From the data, it is clear that the voltage and hence the efficiency remains more or less constant throughout the run implying that the hot side temperature was also changing at a rate similar to the cold side. The possibility still arises that due to the

\footnotetext{
* Corresponding author: m.sajid@smme.nust.edu.pk
} 
constant voltage, the efficiency could depend on factors other than the temperature difference. A key point to note here however is the efficiency which for the $70 \mathrm{~V}$ input voltage which ranges between 0.2 to $0.4 \%$. Compared to the active air cooling method in the wind tunnel which showed a maximum of $4.5 \%$, the active water cooling methods seems significantly inefficient. This goes against the conclusion from Q. Du et al. [6] who, while dealing with active cooling, compared liquid and air cooling and concluded that liquid cooling generated a higher output than air cooling in the case of an internal combustion engine. A possible explanation for this could be that the material that was on the exchanger was not thermally conductive resulting in no or ineffective heat transfer.

The analysis of variance (ANOVA) statistical model was used on the data to analyze the associated variance between the data groups. For the case of the experiment, the data groups were divided into two main divisions; the cooling method and input heat flux and the two different wind speeds for the active air cooling method. The effect analyzed was these factors' influence on the peak efficiency and while the initial claim of the first two factors i.e. cooling method and input heat playing a significant role on the efficiency, was confirmed, the wind speed having no significant contribution to the efficiency was unexpected. It was assumed that due to higher rates of cooling with increasing wind speed, higher wind speeds would yield higher efficiencies. However, since the efficiency depends on the power input and output and not solely the heat transfer, the marginally larger power required for higher wind speeds, balances the peak efficiency between the trails with varying speeds.

Observing all the data it is clear that the only methods to come near the manufacture specification of efficiency are the active air cooling data which reach a maximum of $4.5 \%$ efficiency if peak efficiency is considered. While considering the steady state efficiency however, one should note that the efficiency even with active cooling does not reach $1 \%$ efficiency. Since steady state efficiencies are what we need to consider for long term implementation it should be made clear if the listed efficiencies are for peak or steady state conditions. However from our data, considering steady state efficiencies the cooling methods based on a decreasing efficiency can be listed as follows; active air cooling, active water cooling and passive water cooling.

\section{Conclusion}

From the experiment, the general makeup of the TEG was investigated and the efficiencies for different cooling methods was compared against the manufacturer stated efficiency of $5-8 \%$. While the data points towards air cooling yielding the highest efficiencies both peak and steady state, several anomalies were identified. Possible changes to future experiments include changing the water heat exchanger, allowing for more time between run especially at higher temperatures and

\footnotetext{
* Corresponding author: m.sajid@smme.nust.edu.pk
}

testing different TEG elements to get a better sample space. However, one key point identified was that there should be specifications for whether the efficiencies listed are peak or steady state since for long term use, high steady state efficiencies are paramount. It is clear that due to the longevity, relative durability, small size, lack of moving parts and the simplicity of energy transfer makes TEGs a fast rising and feasible concept for energy generation. Any efforts to employ TEGs in large scale energy generation however need to consider the efficiency of the complete generation system, in addition to that of the thermoelectric device itself.

\section{Acknowledgement}

The authors would like to thank Pavithra Mangapathy, Noor AlAkhawand, Mai Hamed and Mayssaa Jbeili for their contributions to this work.

\section{References}

1. S. J. Blundell and K. M. Blundell, Concepts in Thermal Physics, (Oxford Press, 2006)

2. D. M. Rowe, Appl. Energy, 24, 139 (1986).

3. Y. Apertet, H. Ouerdane, C. Goupil and P. Lecoeur, J. of Appl. Phys. 116, 144901 (2014).

4. U. Sabino, S. Suyitno, I. Ali and E. P. Budiana, Appl. Mech. Mater., 663, 299 (2014).

5. W.-H. Chen, C.-C. Wang and C.-I. Hung, Energy Convers. Manag. 87, 566 (2014).

6. M. JH, W. XD and Z. XX, Appl. Energy, 108, 340 (2013).

7. X. Niu, J. Yu, and S. Wang, J. Power Sources, 188, 621 (2009).

8. M. Gomez, R. Reid, B. Ohara and H. Lee, J. App. Phys. 113, 174908 (2013).

9. F. Guyancourt, [Online]. Available: www.omega.com/temperature/z/pdf/z207.pdf. [2016].

10. M. P. Codecasa, C. Fanciulli, R. Gaddi, F. GomezPaz and F. Passaretti, J. Electron. Mater., 44, 377 (2014).

11. Q. Du, H. Diao, Z. Niu, G. Zhang, G. Shu and K. Jiao, Energy Convers. Manag., 101, 9 (2015).

12. W. He, G. Zhang, X. Zhang, J. Ji, G. Li and X. Zhao, App. Energy, 143, 1 (2015).

13. S.B Riffat and X. Ma, Appl. Therm. Eng., 23, 913 (2003).

14. D. Madan, Z. Wang, P. K. Wright and J. W. Evans, Appl. Energy, 156, 587 (2015).

15. M. V. Lukowicz, T. Schmiel, M. Rosenfeld, J. Heisig and M. Tajmar, J. Electron. Mater., 44, 362 (2014).

16. M. LaMonica, A Thermoelectric Generator That Runs on Exhaust Fumes (IEEE Spectrum 2014).

17. A. Date, A. Date, C. Dixon, R. Singh and A. Akbarzadeh, J. Sol. Energy, 111, 201 (2015). 